\title{
Correction to: A review of the long-term effects of humidity on the mechanical properties of wood and wood-based products
}

\author{
Juan Wang ${ }^{1,2} \cdot$ Xiaoqing Cao $^{1,2} \cdot \mathrm{Haojin} \mathrm{Liu}^{1}$
}

Published online: 11 February 2021

๑) Springer-Verlag GmbH Germany, part of Springer Nature 2021

\section{Correction to: European Journal of Wood and Wood Products \\ https://doi.org/10.1007/s00107-020-01623-9}

In the original publication of the article, the funding number was erroneously published as 54,978,038, but the correct one should be 51,978,038.

This has been corrected in this paper.

The original article can be found online at https://doi.org/10.1007/ s00107-020-01623-9.

Juan Wang

juanwang@bjtu.edu.cn

1 School of Civil Engineering, Beijing Jiaotong University, Beijing 100044, China

2 Beijing's Key Laboratory of Structural Wind Engineering and Urban Wind Environment, Beijing 100044, China 